\title{
SUPREMO TRIBUNAL FEDERAL: A INFORMAÇÃO COMO PRESSUPOSTO NA PROTEÇÃO DO DIREITO À SAÚDE EM TEMPOS DE COVID-19
}

\author{
SUPREME FEDERAL COURT: INFORMATION AS ASSUMPTION IN \\ PROTECTING THE RIGHT TO HEALTH IN COVID -19'S TIMES
}

\author{
Rosana Helena Maas ${ }^{1}$ \\ Anderson Carlos Bosa ${ }^{2}$
}

\begin{abstract}
RESUMO
Considerando a atual crise sanitária global causada pelo COVID-19, pretende-se verificar como o direito à informação age na proteção do direito à saúde e auxilia no enfrentamento da pandemia. Assim, analisa-se o posicionamento do Supremo Tribunal Federal frente ao fornecimento de dados correlacionados ao COVID-19 através das Ações Diretas de Inconstitucionalidades n. 6351, 6347, 6353 e da Medida Cautelar na Arguição de Descumprimento de Preceito Fundamental n. 690, buscando-se, ao final, responder a seguinte problemática: qual é o posicionamento do Supremo Tribunal Federal em relação ao direito à informação na proteção do direito à saúde na atual crise sanitária vivenciada pelo Brasil por conta do COVID-19? Para objetar tal problemática, utiliza-se do método dedutivo e da técnica de pesquisa bibliográfica e jurisprudencial. Constata-se que o Supremo Tribunal Federal se posiciona no sentido de que o direito à informação não pode ser limitado, sendo importante pressuposto para a proteção do direito à saúde, pois a coleta de dados epidemiológicos relacionadas ao COVID-19 constitui mecanismos essenciais para a tomada de decisões, alocação de recursos, efetividade de políticas pública e ações de vigilância epidemiológicas. Ainda, que a não publicidade de determinada informação é excepcional quando determinada pelo interesse público, não podendo transformar a exceção - sigilo - em regra. A importância do trabalho está direcionada ao fator da necessidade de compreender como a proteção ao direito à saúde é sistêmica, abrangendo outros direitos previstos pelo ordenamento jurídico nacional.
\end{abstract}

\footnotetext{
1 Atualmente é Professora da Graduação e Pós-graduação na Universidade de Santa Cruz do Sul (UNISC), ministrando matérias referentes ao Direito e ao Processo Civil e Constitucional. Pós-doutora em Direito pela Universität Salzburg, Áustria (2018), e Doutora em Direito pelo Programa de Pós-Graduação em Direito, Mestrado e Doutorado, da Universidade de Santa Cruz do Sul - UNISC (2016), com doutorado sanduíche na Ernst-MoritzArndt-Universität Greifswald, Rechts und Staatswissenschaftliche Fakultät, Greifswald, Alemanha (2016). É integrante do grupo de estudos Jurisdição Constitucional aberta coordenado pela Profa. Pós-Doutora Mônia Clarissa Hennig Leal. Advogada.

${ }^{2}$ Acadêmico do curso de Direito da Universidade de Santa Cruz do Sul, UNISC, cursando o último ano. Bolsista de iniciação cientifica PROBIC - FAPERGS. Integrante do Grupo de pesquisa "Jurisdição Constitucional aberta: uma proposta de discussão da legitimidade e dos limites da jurisdição constitucional - instrumentos teóricos e práticos", com ênfase em estudos a respeito do diálogo entre Cortes Constitucionais e entre Poderes do Estado, controle jurisdicional de políticas públicas e garantia de direitos humanos e fundamentais na jurisprudência do Supremo Tribunal Federal e da Corte Interamericana de Direitos Humanos. E-mail: andersonn.bosa@ gmail.com
} 


\title{
PALAVRAS-CHAVE:
}

COVID-19. Direito à Informação. Direito à Saúde. Supremo Tribunal Federal.

\begin{abstract}
Considering the actual global sanitary crisis caused by the COVID-10, it is intended to verify how the right to information acts to protect the right to health and helps to face the pandemic. Thus, we analyze the position of the Supreme Court in relation to the provision of data related to COVID-19 through Direct Actions of Unconstitutionalities n. 6351, 6347, 6353 and the Precautionary Measure in the Compliance with Fundamental Precept n. 690, seeking, in the end, to answer the following problem: what is the position of the Supreme Federal Court in relation to the right to information in the protection of the right to health in the current health crisis experienced by Brazil due to COVID-19? To object to this problem, the deductive method and the bibliographic and jurisprudential research technique are used. It appears that the Supreme Federal Court stands in the sense that the right to information cannot be limited, being an important assumption for the protection of the right to health, since the collection of epidemiological data related to COVID-19 are essential mechanisms for the decision-making, resource allocation, public policy effectiveness and epidemiological surveillance actions. Still, that the non-publicity of certain information is exceptional when determined by the public interest, and cannot make exception - confidentiality - a rule. The importance of work is directed to the factor of the need to understand how the protection of the right to health is systemic, covering other rights provided for by the national legal system.
\end{abstract}

\section{KEYWORDS:}

COVID-19. Direct to information. Direct to health. Federal Court of Justice.

\section{INTRODUÇÃO}

Dentro do contexto histórico da humanidade, é possível analisar a ocorrências de diversos problemas sanitários causados pelas mais diversas doenças, tais como: a Gripe Espanhola (1918-1919), Gripe Asiática (1957-1958) e Gripe Russa (1889-1890). Atualmente, vivencia-se a maior crise pandêmica global do século XXI causada pelo novo Coronavirus Diease (COVID-19), onde a evolução dos números de casos e óbitos consequentes do vírus, somado ao fato da ausência de uma vacina pré-existente, ou medicamentos com atuação específica à doença, compreendem um conjunto de informações essenciais para a tomada de decisões e aplicação de políticas de contingência da doença e proteção ao direito à saúde. 
Esse ciclo de informações, que se desenvolve na testagem, passa pelas hospitalizações, casos recuperados e óbitos ocorridos, é registrado e, nas melhores hipóteses, utilizado para fundamentar diversas tomadas de decisões políticas, sociais e científicas para elaborações de respostas, alocações de recursos e avaliação da eficácia de intervenções, como o distanciamento social, o uso de máscaras e a efetividade de possíveis medicamentos e tratamentos para o novo vírus.

À vista disso, o direito à saúde e o direito à informação são consagrados pelo ordenamento constitucional como direitos fundamentais. A Carta Magna de 1988 proclama, no caput de seu artigo 102, que cabe ao Supremo Tribunal Federal a tarefa de seu guardião máximo, cumprindo-lhe, ainda, dizer a última palavra em sede de interpretação das disposições constitucionais e seus conflitos, decidindo-os com base nos princípios constitucionais, principalmente garantindo os direitos fundamentais.

Considerando essas exposições introdutórias, o presente trabalho passa, de início, a estudar o direito à informação e sua correlação na proteção do direito à saúde, para, posteriormente, verificar o posicionamento do Supremo Tribunal Federal (STF) frente ao fornecimento de dados correlacionados ao COVID-19 através das Ações Diretas de Inconstitucionalidades (ADIs) n. 6351, 6347, 6353, ajuizadas por conta da Medida Provisória n. 928/2020, e da Medida Cautelar na Arguição de Descumprimento de Preceito Fundamental (ADPF) n. 690. Onde se verifica a impossibilidade de restrição dos dados correlacionados ao vírus, concluindo pela fundamentalidade do direito à informação para aplicação das mais diversas políticas de combate à doença, assim como, firmando o entendimento de que a exceção da não disponibilização de dados específicos não pode se converter em regra geral.

Dessa forma, utilizando-se do método dedutivo e da técnica de pesquisa bibliográfica e jurisprudencial, almeja-se responder a seguinte problemática: qual é o posicionamento do Supremo Tribunal Federal em relação ao direito à informação na proteção do direito à saúde na atual crise sanitária vivenciada pelo Brasil por conta do COVID-19?

A importância do presente trabalho está direcionada ao fator da necessidade de compreender como a proteção ao direito à saúde é sistêmica, abrangendo outros direitos previstos pelo ordenamento jurídico nacional. 


\section{O DIREITO DE ACESSO À INFORMAÇÃO COMO PRESSUPOSTO NA PROTEÇÃO DO DIREITO À SAÚDE}

Os direitos fundamentais se consagram com o constitucionalismo do século XVIII, embora existam registros importantes de antecedentes históricos para a normatização desses direitos (FERRARI et al., 2016). No Brasil, a Constituição Federal de 1988 consagra-se como marco histórico na previsão dos direitos fundamentais, apresentando o direito à saúde como direito e garantia fundamental social no artigo $6^{\circ}$ e como elemento da ordem social, ao lado do desenvolvimento da sociedade brasileira, no artigo 196 (MAAS et al., 2019). Já o direito fundamental à liberdade de informação está positivado no artigo $5^{\circ}$, incisos XIV e XXXIII e no artigo 220 da Carta Magna (BRASIL, 1988).

A liberdade de informação abrange a procura, o acesso, o recebimento e a difusão de informações ou ideias por qualquer meio, onde não existe dependência de censura (SILVA, 2014). No que tange ao direito à saúde, esse é um dos principais direitos fundamentais sociais encontrados na Lei Maior brasileira, está intrinsicamente ligado ao princípio que rege todo o ordenamento jurídico pátrio, qual seja: o princípio da dignidade da pessoa humana - razão pela qual tal direito merece tratamento especial (CURY, 2005). Dessa forma, saúde é um dever do Estado, garantido mediante políticas sociais e econômicas as quais visem à redução do risco de doenças e outros agravos, bem como o acesso universal e igualitário às ações e serviços para sua promoção, proteção e recuperação, cabendo ao Poder Público dispor sobre a sua regulamentação, fiscalização e controle (MORAES, 2003).

Nessa perspectiva, a dimensão constitucional do direito à informação representa uma peculiaridade da dignidade da pessoa humana, visto que, por meio de informações de qualidade, derivadas de fontes confiáveis, os cidadãos exercem seu direito de autodeterminação (STROPPA, 2010). Além disso, tais informações podem ser utilizadas nos mais diversos âmbitos da sociedade e, no que se refere a efetivação e proteção do direito à saúde, essas informações acabam por refletir nas tomadas de decisões, sejam elas de particulares, no que se pressupõe em como se portar e quais decisões tomar diante de um cenário de crise sanitária a fim de proteger sua saúde ou, então, de entes públicos no que se remete as mais diversas ações governamentais de prevenção, atuação e proteção ao direito à saúde. 
De outra banda, evidencia-se o direito à informação como instrumento indispensável à fiscalização e responsabilização do governo (NOVELINO, 2013); considerando que o ordenamento constitucional é insculpido pelo princípio da publicidade ${ }^{3}$ como um dos vetores imprescritíveis à Administração Pública, conferindo-lhe absoluta prioridade na gestão administrativa e garantindo o pleno acesso a informações a toda a sociedade, a publicidade e a transparência correspondem a obrigatoriedade do Estado em fornecer informações, sob pena de responsabilização política, civil e criminal, salvo nas hipóteses constitucionais de sigilo (LIMBERGER, 2008).

Nesse contexto, a participação dos cidadãos em uma democracia representativa só se fortalece em uma seara de total visibilidade e possibilidade de exposição crítica sobre as políticas públicas adotadas pelos governantes. À vista disso, Holmes Jr. (1988) afirma, com base no seu conhecido pragmatismo, a indispensabilidade do exercício da política de desconfiança (politics of distrust) na construção do pensamento individual e na autodeterminação democrática, para o autônomo desempenho dos direitos de sufrágio e oposição; além da imprescritível necessidade de fiscalização dos órgãos governamentais, que só se torna possível com a garantia da publicidade e transparência. Esse caráter fiscalizador das informações, a exemplo, serve como base de verificação de como, onde e o porquê são aplicados determinados investimentos nas políticas de saúde.

Assim, o direito fundamental à informação estende-se em três níveis: o direito de informar, o direito de se informar e o direito de ser informado. O primeiro se estrutura na liberdade de transmitir ou comunicar informações a terceiro, de as disseminar sem impedimentos, mas também pode se revestir de forma positiva enquanto direito a informar, ou seja, direitos a meios para informar. $\mathrm{O}$ direito de se informar se amolda, designadamente, na liberdade de buscar informações, de pesquisa de fontes, isto é, no direito de não ser impedido de se informar. E o direito de ser informado é a versão positiva do direito de se informar, emoldando-se num direito a ser mantido adequadamente e verdadeiramente informado, desde logo, pelos meios de comunicação e pelos poderes públicos (CANOTILHO et al., 1993).

3 Considerando a prevalência do princípio da publicidade dos atos administrativos no ordenamento brasileiro, valido pelo Art. 37, caput, da Constituição Federal, o qual estabelece que: Art. 37. A administração pública direita e indireta de qualquer dos Poderes da União, do Estado, do Distrito Federal e dos Municípios obedecerá aos princípios de legalidade, impessoalidade, moralidade, publicidade e eficiência e, também, ao seguinte: [...] (BASIL, 1988, http://www.planalto.gov.br/ccivil_03/constituicao/constituicao.htm). 
Nesse ínterim, ao estudar as garantias dos direitos, discorre-se sobre o poder político que é assentado pelo direito mutuamente. Isso indica um nexo que ocasiona a instrumentalização do direito para o exercício estratégico e dinâmico do poder. Habermas (2012) escreve sobre a ideia de que o Estado de Direito exige como contrapartida, uma organização estrutural do Poder Público que obriga o Poder Político, alicerçado conforme o direito, a se legitimar, por sua vez, pelo direito legitimamente instituído. Com isso, no sistema da Administração Pública, concentra-se um poder que precisa se reestruturar a cada passo a partir do poder comunicativo, pois o direito não é apenas constitutivo para o código do poder que dirige o processo de administração: ele institui o meio para a transformação do poder comunicativo em administrativo.

Aqui, é possível obter a ideia do Estado de Direito na percepção em que o direito legítimo é produzido através do poder de comunicação, que, por seu turno, é modificado em poder administrativo pelo direito legitimamente normatizado.

Nessa ordem, o Estado Democrático de Direito surge através do espaço jurídico e político, o que ocasiona o desenvolvimento de ações sociais e políticas. Por esta razão, o Estado de Direito formula-se pela ordem jurídica, abarcando o direito à informação, que não se restringe a mero aspecto moral, mas também formal e material. Cabendo aos entes federados considerar que seu poder administrativo cria um espaço de construção sobre os caminhos e decisões a serem tomadas em relação à sociedade e governo, garantindo, por meio da informação, um espaço de discussão de questões as quais cercam toda a comunidade e que abrange a concretização dos planos de executividade e avaliação das questões pertinentes. Com essa ideia, e a fim de concretizar e regulamentar o direito fundamental a livre informação, transformando o poder comunicativo em administrativo, criou-se a Lei de Acesso à Informação n. $12.527 / 2011$ (LAI).

A LAI prevê os procedimentos que devem ser observados pela Administração Pública com o escopo de concretizar o acesso à informação. O mencionado dispositivo legal apresenta como diretrizes a organização da participação popular frente às informações disponibilizadas pelos órgãos públicos e a construção de estruturas as quais possibilitem a criação de canais de acesso dessas informações (SEABRA et al., 2012). Nessa exegese:

[...] só se pode investir alguém no direito de receber informações quando simultaneamente atribuir-se a outrem o dever de informar. Nessa matéria, a 
Constituição Federal foi terminante ao atribuir exclusivamente ao Poder Público (art. $5^{\circ}$, XXXIII, e 37, caput) o dever de informar. Assim sendo, pode-se concluir que o direito de ser informado assume dois sentidos. Primeiro, o direito de receber as informações veiculadas sem interferência estatal, numa interface com o direito de informar. Segundo, o direito de ser mantido constantemente informado sobre os negócios e atividades públicas (ARAÚJO et al., 2004, p. 120).

Segundo a LAI, a regulamentação do acesso à informação envolve procedimentos fundamentais que asseguram esse direito, sendo necessário que sejam executados de acordo com os princípios básicos da Administração Pública, com foco em promover a publicidade como preceito geral e o sigilo como exceção. No que tange as informações de interesse público, em conformidade com a LAI, essas deverão ser divulgadas livremente pelas instituições, mesmo que não sejam solicitadas (KRAMER et al., 2015).

Para isto, faz-se necessário o uso de meios de comunicação disponibilizados pela tecnologia da informação, assegurando um mecanismo que promova a segurança dos dados para que o sistema não seja invadido e modificado. O corpo legislativo da LAI, apresenta dispositivos para o estímulo ao progresso da cultura de transparência na Administração Pública, devendo ser adotados procedimento os quais sejam aderidos voluntariamente pelas instituições, respeitando o desenvolvimento do controle social da Administração Pública (BRASIL, 2011).

Outrossim, o complexo normativo da LAI conceitua o conjunto de informações como sendo ações direcionadas à produção, transporte, transmissão, distribuição, arquivamento, armazenamento, eliminação, avaliação, destinação ou controle da informação, dentre outras. Para isso, tendo o Estado o dever de garantir o direito de acesso à informação, a LAI prevê que o acesso deve obedecer a procedimentos eficazes, transparentes, objetivos e de fácil compreensão. Sendo obrigatório, segundo seu artigo $9^{\circ}$, a divulgação em sites oficiais da internet (BRASIL, 2011).

Outro aspecto importante da LAI é o estabelecimento da transparência ativa e passiva na Administração Pública. A primeira é compreendida como a exigência de órgãos e entidades públicas de divulgar, de maneira espontânea, independente de terem sido requisitadas informações de interesse geral. A segunda, refere-se à criação dos Serviços de Informação do Cidadão (SIC), ou seja, é um canal efetivo em que a sociedade pode apresentar à Administração Pública sua demanda de informação (KRAMER et al., 2015). 
Em consonância com o Decreto n 7.724, de 16 de maio de 2012, que regula a LAI, o Capítulo III ao falar sobre a transparência ativa, determina que as informações deverão ser disponibilizadas em sites oficiais da internet de órgãos públicos e entidades públicas independentemente de requerimentos. O Capítulo IV do Decreto, trata da transparência passiva compreendendo a SIC como forma de fornecer, orientar e atender o público; informar sobre o trâmite de documentos; e receber e realizar o registro de pedidos de acesso à informação (BRASIL, 2012).

Conseguinte, a LAI estabelece, em seu artigo 11 (BRASIL, 2011, http://www.planalto.gov.br/ccivil_03/_ato2011-2014/2011/lei/112527.htm), que o "órgão ou entidade pública deverá autorizar ou conceder o acesso imediato à informação disponível", posto que se não for possível disponibilizar o acesso imediato, o órgão ou entidade requerida deverá, em um prazo máximo de vinte dias, podendo ser prorrogado por mais dez dias mediante justificativa expressa, (i) comunicar data, local e modo para a realização da consulta, consumar sua reprodução ou obter certidão; (ii) evidenciar as razões de fato ou de direito da recusa total ou parcial do acesso pretendido; ou (iii) indicar que não possui a informação solicitada.

Em caso de indeferimento de acesso à informação, a LAI estipula prazo de dez dias a contar da sua ciência para propositura de recurso pelo interessado, devendo à autoridade hierarquicamente superior se manifestar em um prazo de cinco dias. Após manifestação da autoridade hierarquicamente superior, no caso de negativa ao acesso à informação pelos órgãos ou entidades do Poder Executivo Federal, o solicitante poderá recorrer à Controladoria-Geral da União, que deliberará no prazo de cinco dias se (i) a disponibilização da informação não classificada como sigilosa; (ii) a decisão de negativa de acesso à informação total ou parcial classificada como sigilosa não indicar a autoridade classificadora ou a hierarquicamente superior a quem possa ser direcionado pedido de acesso ou desclassificação; (iii) os procedimentos de classificação de informação sigilosa estabelecidos pela LAI não tiverem sido observados; e (iv) estiverem sendo descumpridos prazos ou demais procedimentos da LAI (BRASIL, 2011).

O artigo 21, da LAI também prevê a impossibilidade de negativa ao acesso a informações necessárias à tutela judicial ou administrativa de direitos fundamentais. Da mesma forma que classifica, em seu artigo 23, à informação quanto ao grau e prazos de sigilo, que são exceções dentro da publicidade e transparência, determinando no artigo 24 essas informações 
como ultrassecretas pelo prazo de vinte e cinco anos, secretas pelo prazo de quinze anos ou reservadas pelo prazo de cinco anos (BRASIL, 2011).

Diante de todo o exposto, ao estudar o direito à informação, observa-se que a pandemia causada pelo COVID-19 tem produzido uma quantidade massiva de dados. Na medida em que os mais diversos países buscam construir cenários realistas, observando o concreto nível do problema, as entidades cientificas realizam coletas de dados e sistematizam informações sobre a atuação do vírus, empreendendo esforços de modelagem a fim de presumir a carga pandêmica e as necessidades de prestações de saúde.

Portanto, é possível dimensionar a importância da divulgação de dados informativos relacionados ao COVID-19, como sendo ferramentas essenciais na elaboração de respostas, alocação de recursos e avaliação de eficácia de intervenções, além de ser um direito fundamental - atuando aqui, como pressuposto de outros direitos fundamentais, no caso, o direito à saúde e à vida.

Com isso, não existem dúvidas que a disponibilidade de dados de forma aberta e transparente, respeitando os princípios e direitos constitucionais, aparece como fundamental para o combate da pandemia. Entretanto, alguns entraves impostos por decisões políticas e administrativas, têm causado determinadas limitações ao acesso a informações e ações em saúde no Brasil correlacionadas ao vírus, exigindo uma atuação contundente por parte do judiciário na garantia do dever ao acesso à informação.

É com isso, que o presente trabalho passa a dissertar sobre o posicionamento do STF em relação a divulgação de dados relacionados ao COVID-19, tendo em vista as ADIs n. 6351, 6347, 6353, provenientes da edição da Medida Provisória n. 928/20 e que, entre outros pontos, alterou a observância de prazos na disponibilidade de informações, alterou o modo de recuso em caso de negativa e criou outros empecilhos, e da Medida Cautelar na ADPF n. 690. 


\section{UMA ANÁLISE DO POSICIONAMENTO DO STF EM RELAÇÃO A DIVULGAÇÃO DE DADOS CORRELACIONADOS AO COVID-19}

Em 11 de março de 2020, a Organização da Saúde (OMS) declarou como pandemia a doença causada pelo COVID-19. Devido a situação de desconhecimento dos mais diversos fatores da doença, tais como as formas de contágio, método de prevenção, vacinas, entre outros, bem como instrumentos para o auxílio no tratamento e na cura, emergem medidas não farmacêuticas criadas pelo Estado com o escopo de enfrentar o atual cenário sanitário crítico social (UCHÔA et al., 2020).

O governo brasileiro, procurando combater a situação causada pela doença, emitiu diversos dispositivos legais em resposta ao vírus e a crise por esse causada, buscando enquadrar a sociedade brasileira no atual cenário de pandemia mundial. Houve uma forte movimentação legislativa, tanto no âmbito federal, estadual e municipal, tendo destaque a produção da Lei n. 13.979, de 06 de fevereiro de 2020, que dispõe sobre as medidas para enfrentamento da emergência de saúde pública decorrente do COVID-19 (BRASIL, 2020a).

Em seguida, o governo federal criou a Medida Provisória n. 928 de 28 de março de 2020, que, como se verá a seguir, foi suspensa por decisão do STF, e, entre outros pontos, incluiu através de seu artigo $1^{\circ}$ o artigo $6^{\circ}$-B no texto da Lei n. 13.979/20, o qual modifica a LAI, alterando prazos de respostas, alterando disposições em relação a recursos nos casos de negativas de acesso à informação, entre outros balizadores os quais dificultam o acesso à informação. De acordo com o texto do respectivo dispositivo:

Art. $6^{\circ}$-B. Serão atendidos prioritariamente os pedidos de acesso à informação, de que
trata a Lei $n^{\circ} 12.527$, de 2011 , relacionados com medidas de enfrentamento da
emergência de saúde pública de que trata esta Lei. $\S 1^{\circ}$ Ficarão suspensos os prazos
de resposta a pedidos de acesso à informação nos órgãos ou nas entidades da
administração pública cujos servidores estejam sujeitos a regime de quarentena,
teletrabalho ou equivalentes e que, necessariamente, dependam de: I acesso presencial
de agentes públicos encarregados da resposta; ou II agente público ou setor
prioritariamente envolvido com as medidas de enfrentamento da situação de
emergência de que trata esta Lei. $\S 2^{\circ}$ Os pedidos de acesso à informação pendentes
de resposta com fundamento no disposto no $\S 1^{\circ}$ deverão ser reiterados no prazo de
dez dias, contado da data em que for encerrado o prazo de reconhecimento de
calamidade pública a que se refere o Decreto Legislativo $n^{\circ} 6$, de 20 de março de 2020 .
$\S 3^{\circ}$ Não serão conhecidos os recursos interpostos contra negativa de resposta a pedido
de informação negados com fundamento no disposto no $\S 1^{\circ}$. $\S 4^{\circ}$ Durante a vigência
desta Lei, o meio legítimo de apresentação de pedido de acesso a informações de que 
trata o art. 10 da Lei $\mathrm{n}^{\circ} 12.527$, de 2011, será exclusivamente o sistema disponível na internet. $\S 5^{\circ}$ Fica suspenso o atendimento presencial a requerentes relativos aos pedidos de acesso à informação de que trata a Lei n ${ }^{\circ}$ 12.527, de 2011 (BRASIL, 2020a, http://www.planalto.gov.br/ccivil_03/_ato2019-2022/2020/lei/113979.htm)

Segundo informações divulgadas pela Controladoria-Geral da União, a Medida Provisória que incluiu o artigo $6^{\circ}-\mathrm{B}$, na Lei n. 13.979/20, justificar-se-ia pela abrangência nacional da LAI, “estando muitas prefeituras do país em situação delicada de pessoal”. Também mencionando que os prazos da LAI seriam observados quando for possível a formatação de resposta digital (BRASIL, 2020b).

Tendo em vista os questionamentos de inconstitucionalidade do mencionado dispositivo, foram protocoladas três Ações Diretas de Inconstitucionalidades junto ao STF, buscando a suspensão da norma trazida pela Medida Provisória 928, quais sejam: ADI 6.347, ADI 6.351 e ADI 6.353.

Na ADI n. 6.347, ajuizada pelo Partido Rede Sustentabilidade, fundamentou-se que o artigo $6^{\circ}$-B violava os artigos $5^{\circ}$, XXXIII; 37, § $3^{\circ}$, II; e 216, §2 , da Constituição Federal. Ademais, foi alegado que o dispositivo limitava o direito à informação por (i) suspender os prazos de resposta a pedidos de acesso à informação; (ii) impedir o conhecimento de recursos interpostos contra essa negativa de resposta; e (iii) dificultar seu posterior acesso, por exigir a necessidade de reiteração do pedido quando cessado o estado de calamidade pública. Por fim, aduziu que a nova regra mitigava o controle social às ações públicas por se caracterizar como um obstáculo desproporcional e não razoável ao direito de acesso à informação (BRASIL, 2020c)

Prosseguindo, tem-se a proposta pelo Conselho Federal da Ordem dos Advogados do Brasil (CFOAB), a ADI n. 6.351, o qual impugnou a nova regra por considerar que essa regra

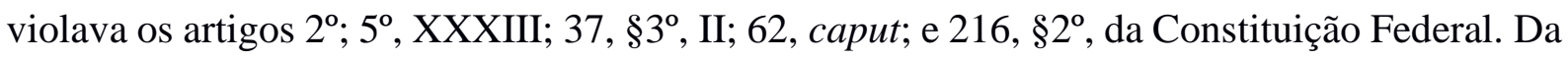
mesma forma, que sustenta a inconstitucionalidade formal e material do dispositivo (BRASIL, 2020c).

No que refere ao vício formal, aludia que a LAI já apresentava em seu artigo $11, \S 1^{\circ}$, II, norma a ser aplicável em um cenário de crise como a vivenciada pelo COVID-19, o que afastaria a necessidade de atropelamento do devido processo legislativo para a edição da 
Medida Provisória. De outra banda, mencionava à inexistência de motivos em comprovar os requisitos do artigo 62, caput, da Carta Mana (relevância e urgência) (BRASIL, 2020c).

Materialmente, a ADI n. 6.351 argumentava que por (i) suspender os prazos de respostas a requerimentos de acesso à informação; (ii) contrapor o devido processo legal ao vetar o conhecimento de recursos protocolados contra essa negativa de resposta; (iii) instituir obrigação excessiva ao cidadão por exigir a reiteração do pedido quando cessado a calamidade provocada pelo COVID-19; e (iv) existir forma menos gravosa de lidar com o respectivo tema em circunstâncias como as causadas pelo COVID-19 prevista na LAI, a Medida Provisória limitaria os direitos constitucionais à informação, à transparência e à publicidade (BRASIL, 2020c).

Já a ADI n. 6.353, protocolada pelo Partido Socialista Brasileiro (PSB), alegava a inconstitucionalidade da matéria por ofensa aos artigos. $5^{\circ}$, XXXIII, XXXIV, LIV e LV; e 37, caput e $\$ 3^{\circ}$, II, da Constituição Federal. Justificando que a regra acaba por impedir a aplicação da LAI a setores da Administração Pública ao (i) impedir de forma ilógica o acesso à informação; (ii) flexibilizar o dever da Administração Pública de efetivar o acesso à informação; e (iii) retirar a possibilidade de recurso contra atos que denegarem resposta às solicitações com base na LAI (BRASIL, 2020c).

Diante das referidas alegações, o STF, por meio da relatoria do Ministro Alexandre de Moraes, concedeu, em julgamento conjunto, Medida Cautelar a todas as ADIs, suspendendo a eficácia do artigo $6^{\circ}-\mathrm{B}$, da Lei n. 13.979/20. O voto proferido pelo Ministro também foi no sentido de referendar a Medida Cautelar concedida sob a justificativa de que na hipótese da norma objeto das ações, essa acabava por transformar a exceção - sigilo de informações - em regra, afastando a incidência dos princípios da publicidade e da transparência. Além disso, a publicidade específica de determinada informação só poderá ser negada em caso de pleno interesse público. Nesse caso, a Administração Pública tem a obrigação de manter transparência absoluta nos negócios públicos, isso sob pena de desrespeito aos artigos 37 , caput, e $5^{\circ}$, incisos XXXIII e LXXII (BRASIL, 2020c).

De outra banda, o Ministério da Saúde passou a retardar a divulgação dos dados sobre a pandemia do COVID-19, alterando o formato do balanço diário da COVID-19, acabando por omitir dados de suma importância sobre a atuação do vírus, tendo retirado temporariamente o site de divulgação dos números correlacionados à doença. Da mesma forma, que o Ministério 
alterou o funcionamento do aplicativo Coronavírus - SUS, não emitindo dados sobre o vírus (BRASIL, 2020d).

Frente a isso, os partidos políticos Rede Sustentabilidade, Partido Comunista do Brasil - PCdoB e Partido Socialismo e Liberdade - PSOL, ajuizaram, junto ao STF, Medida Cautelar na ADPF n. 690, que também teve como relator o Ministro Alexandre de Moraes.

Em síntese, sustentaram que ocorreu uma mudança injustificável na prática adotada pelo Ministério da Saúde no que tange a divulgação dos dados referentes ao COVID-19, sendo que, a retenção dessas importantíssimas informações inviabiliza o acompanhamento do avanço do vírus no Brasil, acabando por atrasar a correta implantação de política pública sanitária de controle e prevenção da doença. Com isso, alegaram a violação a preceitos fundamentais da Constituição, sobretudo o direito à vida e à saúde, além do dever de transparência (BRASIL, 2020d).

Tendo em vista que o direito à vida e à saúde se mostram como consequência direta da dignidade da pessoa humana e como um dos fundamentos da República Federativa do Brasil, deve-se concretizar o direito à saúde como dever do Estado e direito de todos, garantindo sua universalidade e igualdade no acesso às ações e serviços de saúde. Para isto, a Constituição Federal prevê princípios informadores e normas de competência no tocante à proteção à saúde pública, destacando seu próprio preâmbulo onde é mencionado a necessidade de o Estado Democrático assegurar o bem-estar da sociedade (BRASIL, 2020d).

Destarte, intrínseco a ideia de bem-estar, deve ser salientada como uma das principais finalidades do Estado a efetividade de políticas públicas destinadas à saúde, inclusive a obrigação constitucional do SUS de executar as ações de vigilância epidemiológica, dentre elas, o fornecimento de todas as informações necessárias para o devido planejamento e combate à pandemia causada pelo COVID-19. Assim, a gravidade causada pela pandemia do COVID-19, exige das autoridades públicas, de todos os níveis da federação, a efetivação concreta da proteção à saúde pública, com a adoção de todas as medidas possíveis para o apoio e manutenção da saúde da população (BRASIL, 2020d).

Para tanto, o país deve adotar medidas de efetividade internacionalmente reconhecidas, dentre elas, coleta, análise, armazenamento e divulgação de relevantes dados epidemiológicos 
necessários, tanto ao planejamento do poder público para escolha de decisões e o andamento de políticas públicas, quanto do devido acesso da sociedade para o efetivo conhecimento da situação vivenciada pelo Brasil. É por esses motivos, que a Constituição Federal consagrou expressamente o princípio da publicidade como um dos vetores imprescritíveis à Administração Pública (BRASIL, 2020d).

À vista disso, e pelo grave risco de uma cessão abrupta do recolhimento e divulgação de importantes dados epidemiológicos imprescindíveis para a manutenção da análise da série histórica de evolução da pandemia no país, o STF concedeu parcialmente a Medida Cautelar na ADPF n. 690. Com isso, foi determinado ao Ministro da Saúde em exercício que mantivesse, em sua integralidade, a divulgação diária dos dados epidemiológicos relativos à pandemia, inclusive no sítio do Ministério da Saúde e com os números acumulados de ocorrências, exatamente conforme era procedido até então (BRASIL, 2020d).

Nesse aspecto, "a informação é elemento essencial e determinante de todos os campos do conhecimento" (MARIZ, 2012, p. 21). Por isso, contém suma importância em diversos campos da sociedade, sendo instrumento relevante para a criação de políticas públicas de qualidades, não apenas no ramo do direito à saúde e na atual crise sanitária vivenciada pelo Brasil e pelo mundo, mas também nos diversos ramos da sociedade provida de um Estado Democrático de Direito.

Por esse ângulo, o posicionamento do STF quanto à efetivação do direito à informação como forma de proteção ao direito à saúde na atual crise vivenciada, é firme ao destacar a fundamentalidade do acesso à informação em todas as circunstâncias. Não podendo o Estado restringir direitos fundamentais, principalmente em momentos de crise em que a sociedade participativa só pode colaborar em um âmbito de transparência, da mesma forma, que as políticas de contingências dependem de informações para a sua ideal aplicabilidade e funcionamento, observando a proteção do direito à saúde, da vida e da dignidade da pessoa humana.

O Supremo Tribunal Federal afirma que o direito à informação não pode ser limitado, sendo importante pressuposto para a proteção sistêmica do direito à saúde, uma vez que a coleta de dados correlacionados ao COVID-19 constitui mecanismos essenciais para a tomada de decisões, alocação de recursos, efetividade de políticas públicas e ações de vigilância 
epidemiológicas. Ainda, que a publicidade específica de determinada informação somente poderá ser excepcional quando o interesse público assim determinar, não podendo transformar a exceção - sigilo - em regra.

Por fim, o direito de acesso à informação age como pressupostos da garantia e de proteção de todo e qualquer direito fundamental, de eficácia e de eficiência de políticas públicas de qualquer natureza, enfatizando-se, aqui, o direito à saúde.

\section{CONSIDERAÇÕES FINAIS}

Em vista do maior desafio sanitário do século, o Brasil, assim como o mundo todo, tem assistido à evolução dos números de casos de óbitos e de infectados pelo novo COVID-19, como consequência, denota-se diversas alterações na rotina da população e nas políticas de controle do novo vírus. Todas essas mudanças geram um ciclo de informações que inicia desde as testagens, estudos da atuação do vírus, hospitalizações, números de infectados, números de leitos na UTI, números de recuperados, números de óbitos, entre outros.

Essas informações devem ser utilizadas em diversas searas da sociedade, não apenas em períodos de crises sanitárias como o atual, mas também em políticas públicas permanentes de controle das mais variadas doenças. Isso, posto que, diante da tutela do direito à saúde da população, esses dados influenciam objetivamente nas escolhas de medidas e decisões a serem tomadas, tanto em caráter particular, quanto coletivo - na ordem de políticas públicas.

Por esse ângulo, como visto, a liberdade de informação compreende à procura, ao acesso, ao recebimento e à difusão dos mais diversos dados, informações e ideias por qualquer meio em que não se configure a existência de sujeição de censura. Considerando tal conjectura, o aspecto normativo constitucional do direito à informação reflete uma especificidade da dignidade da pessoa humana, estruturada pela compreensão de que através de informações de excelência, provenientes de fontes confiáveis, a população exercita sua autonomia. 
Nessa seara, o direito à saúde e o direito à informação são garantias fundamentais apresentadas pela Carta Magna de 1988 e regulamentados por dispositivos infraconstitucionais, cabendo ao Estado a obrigatoriedade de efetivá-los. Por meio desta dinâmica, tem-se circunstâncias em que nem sempre União, Estados e Municípios trabalham de forma a preservar e efetivar os respectivos direitos constitucionais, cabendo ao STF o papel de proteger e decidir a respeito dos conflitos criados dentro do Estado em relação aos princípios e normas fundamentais.

Diante disto, o presente trabalho passou, de início, a analisar o direito à informação e sua correlação na proteção do direito à saúde, para, em seguida, observar o posicionamento do STF diante do fornecimento de dados correlacionados ao COVID-19 através das ADIs n. 6351, 6347, 6353 e da Medida Cautelar na ADPF n. 690.

Percebe-se que o Estado Democrático de Direito nasce por intermédio do plano jurídico e político, o que resulta na construção de ações sociais, administrativas e políticas. À vista disso, o Estado de Direito baseia-se pela ordem jurídica, englobando o direito à informação de maneira paralela ao direito à saúde, os quais não se limitam a meros aspectos morais, mas também formais e materiais. Fixa-se com isso, o entendimento de que os Entes Federados necessitam analisar que seu poder administrativo forma um terreno de construção sobre os caminhos e decisões a serem tomadas em relação à sociedade e governo, permitindo um espaço de debates de pontos os quais permeiam toda a sociedade e que determinam a realização de táticas de executividade e avaliação das respectivas questões pertinentes.

Para isso, estudou-se que, com o escopo de regularizar o direito fundamental a livre informação prevista constitucionalmente, transformando o poder comunicativo em administrativo, tem-se a Lei e Acesso à Informações (LAI) n. 12.527/2011, que buscou prever os procedimentos os quais devem ser observados pela Administração Pública com o propósito de concretizar o acesso à informação. Tal dispositivo legal, possuí como diretrizes a organização da participação popular diante das informações disponibilizadas pelos órgãos públicos e a construção de estruturas que permitam arquitetar caminhos que viabilizem a criação de canais de acesso destas informações.

Dessa forma, tendo em consideração a problemática proposta no presente trabalho, conclui-se que o Supremo Tribunal Federal posiciona-se no sentido de compreender que o 
direito à informação não pode ser limitado, sendo importante pressuposto para a proteção sistêmica do direito à saúde, uma vez que a coleta de dados correlacionadas ao COVID-19 constituem mecanismos essenciais para a tomada de decisões, alocação de recursos, efetividade de políticas públicas e ações de vigilância epidemiológicas. Ainda, que a não publicidade específica de determinada informação somente poderá ser excepcional quando o interesse público assim determinar, não podendo transformar a exceção - sigilo - em regra.

Com isso, o posicionamento do STF, quanto à tutela do direito à informação como meio de proteção ao direito à saúde na contemporânea crise sanitária global, é sólida ao enaltecer a essencialidade do acesso à informação em múltiplas hipóteses, fundamentalmente em momentos de crise. Sendo que, as políticas de contingência dependem de informação para a sua ideal aplicabilidade e funcionamento, observando a proteção do direito à saúde, da vida e da dignidade da pessoa humana.

Ademais, advoga-se nesse sentido, que o direito de acesso à informação age como pressuposto de garantia do direito à saúde, bem como de outros direitos fundamentais, sendo ambos os direitos além de deveres (proteção) do Estado, muito mais, direitos dos cidadãos. Portanto, denota-se que a importância da pesquisa está direcionada ao fator de compreender e demonstrar como a proteção ao direito à saúde é sistêmica, abrangendo outros direitos previstos pelo ordenamento jurídico nacional.

\section{REFERÊNCIAS BIBLIOGRÁFICAS}

ARAÚJO, L.A.D., et al. Curso de direito constitucional. 8. ed. São Paulo: Saraiva, 2004.

BRASIL. [Constituição, (1988)]. Constituição da República Federativa do Brasil. Brasília, DF: Presidência da República, [2020]. Disponível em: http://www.planalto.gov.br/ccivil_03/constituicao/constituicao. Acesso em: 13 de ago. 2020.

BRASIL. Decreto n. 7.724, de 16 de maio de 2012. Regulamenta a Lei $\mathrm{n}^{\circ} 12.527$, de 18 de novembro de 2011, que dispõe sobre o acesso a informações previsto no inciso XXXIII do caput do art. $5^{\circ}$, no inciso II do $\S 3^{\circ}$ do art. 37 e no $\S 2^{\circ}$ do art. 216 da Constituição. Brasília,
DF:
Presidência
da República,
[2019].
Disponível
em: http://www.planalto.gov.br/ccivil_03/_ato2011-2014/2012/decreto/d7724.htm. Acesso em: 10 de ago. de 2020. 
BRASIL. Lei 13.979, de 06 de fevereiro de 2020 (a). Dispões sobre as medidas para enfrentamento da emergência de saúde pública de importância internacional decorrente do coronavírus responsável pelo surto de 2019. Brasília, DF: Presidente da República, [2020]. Disponível em: http://www.planalto.gov.br/ccivil_03/_ato2019-2022/2020/lei/113979.htm. Acesso em: 10 ago. 2020.

BRASIL. Lei 12.527, 18 de novembro de 2011. Regula o acesso a informações previsto no inciso XXXIII do art. 5o, no inciso II do § 3o do art. 37 e no $§ 20$ do art. 216 da Constituição Federal; altera a Lei no 8.112, de 11 de dezembro de 1990; revoga a Lei no 11.111, de 5 de maio de 2005, e dispositivos da Lei no 8.159, de 8 de janeiro de 1991; e dá outras providências. Brasília, DF: Presidência da República, [2019]. Disponível em: http://www.planalto.gov.br/ccivil_03/_ato2011-2014/2011/lei/112527.htm. Acesso em: 14 jul. 2020.

BRASIL. Supremo Tribunal Federal. Medida Cautela de Descumprimento de Preceito Fundamental n. 690 Distrito Federal. Sequência de atos do Poder Executivo Federal que restringiram a publicidade dos dados relacionados à covid-19, em clara violação a preceitos fundamentais da Constituição Federa. [...] Requerentes: Rede Sustentabilidade, Partido Socialismo e Liberdade (P-SOL) e Partido Comunista do Brasil. Intimado: Ministro de Estado da Saúde. Relator: Alexandre de Moraes, 08 de junho de 2020 (d). Disponível em: http://www.stf.jus.br/arquivo/cms/noticiaNoticiaStf/anexo/ADPF690cautelar.pdf. Acesso em: 13 ago. 2020.

BRASIL. Supremo Tribunal Federal. Referendo na Medida Cautelas na Ação Direta de Inconstitucionalidade n. 6.351, 6.347 e 6.353 Distrito Federal. CONSTITUCIONAL E ADMINISTRATIVO. Restrições genéricas e abusivas à garantia constitucional de acesso à informação. [...] Requerente: Conselho Federal da Ordem dos Advogados do Brasil. Intimado: Presidente da República. Relator: Min. Alexandre de Moraes, 30 de abril de 2020 (c). Disponível em: http://portal.stf.jus.br/processos/detalhe.asp?incidente=5881853. Acesso em: 10 ag. 2020.

CANOTILHO, José Joaquim Gomes, et al. Constituição da república portuguesa anotada. 3. ed. Coimbra: Coimbra Editor, 1993.

CURY, Leda Tatiana. Direito fundamental à saúde: evolução, normatização e efetividade. Rio de Janeiro: Lúmen Júris, 2005.

FERRARI, C.C. et al. O direito à informação como direito fundamental ao Estado Democrático. Rev. Direitos Sociais e Políticas Públicas (UNIFAFIBE), ISSN 2318-5732, v. 4, n. 2, 2016. Disponível em: http://www.unifafibe.com.br/revista/. Acesso em: 10 de ago. 2020.

GOVERNO FEDERAL. Controladoria-Geral da União. Governo estabelece alterações em prazos de atendimento da LAI. Gov.br, Governo Federal, Brasília, DF, 23 mar. 2020 (b). Disponível em:<https://www.gov.br/cgu/pt-br/assuntos/noticias/2020/03/governo-estabelecealteracoes-em-prazos-de-atendimento-da-lai >. Acesso em: 10 ago. 2020.

HABERMAS, Jurgen. Direito e Democracia: entre facticidade e validade. Tradução: Flávio B. Siebeneichler. Rio de Janeiro, 2012. 
HOLMES JÚNIOR, Oliver Wendell. The Mind and Faith os Justice Holmes: His Speeches, Essays, Letters, and Judicial Opinions. 2. ed.. New York: Dover, 1988.

KRAMER, G. P., et al. O acesso à informação como fonte de conhecimento e transparência pública a luz da Lei n. 12.527/2011: O caso da Justiça Federal da cidade do Rio Grande. Rev. Ágora. ISSN 0103-3557, Florianópolis, v. 25, n. 51, p. 354-376, jul./dez., 2015. Disponível em: http://www.periodicos.unc.br/index.php/agora. Acesso em: 10 ago. 2020.

LIMBERGER, Têmis. Transparência administrativa e novas tecnologias: o dever de publicidade, o direito a ser in-fmado e o princípio democrático. Rev. Do Ministério Público do RS. Porto Alegre, n. 60, ago.2007/abr.2008, p. 47-65, 2008. Disponível em: https://www.mprs.mp.br/biblioteca/revistamp. Acesso em: 10 de ago. 2020.

MAAS, R. H., et al. O fornecimento de medicamentos sem registro na ANVISA: Uma análise frente aos critérios estabelecidos pelo STF. Rev. Direitos Sociais e Políticas Públicas (UNIFAFIBE). ISSN 2318-57-32 - vol. 8, n. 2, 2020, p. 340-370. Disponível em: http://www.unifafibe.com.br/revista/index.php/direitos-sociais-politicas-pub/issue/view/39.

Acesso em: 13 ago. 2020.

MARIZ, Anna Carla A. A Informação na Internet. Arquivos públicos brasileiros. Rio de Janeiro, 2012.

MORAES, Alexandre de. Direito constitucional. 13. ed. São Paulo: Atlas, 2003.

NOVELINO, Marcelo. Manual de direito constitucional. 8 ed. São Paulo: Método, 2013.

SEABRA, S.N., et al. Lei de Acesso à Informações: uma análise dos fatores de sucesso da experiência do poder executivo federal. Rev. de Administraçãa Municipal - IBAM. vol. 58, n. 282. Rio de Janeiro, 2012, p. 18-26. Disponível em: https://issuu.com/ibam/docs/ibam_282completa. Acesso em: 13 ago. 2020.

SILVA, José Afonso da. Curso de Direito Constitucional Positivos. 37 ed.. São Paulo: Malheiros Editores, 2014.

STROPPA, Tatiana. As dimensões constitucionais do direito de informação e o exercício da liberdade de informação jornalística. Belo Horizonte: Fórum, 2010.

UCHÔA, S.B.B., et al. Coronavírus (COVID-19): Um exame constitucional e ético das medidas previstas na Lei n. 13.979, de 06 de fevereiro de 2020. Rev. Cadernos de Prospecção. Salvador, vol. 13, n.2, Edição Especial, p. 441-458, abril, 2020. Disponível em: https://portalseer.ufba.br/index.php/nit/article/view/36163/20967. Acesso em: 13 ago. 2020.

Data de Submissão: 20/12/2020

Data de Aceite: 22/03/2021 